\title{
Heavy Lake-Effect Snowfall Changes and Mechanisms for the Laurentian Great Lakes Region
}

\author{
Oleksandr Huziy ${ }^{1,2, *}$, Bernardo Teufel ${ }^{1,2}{ }^{\mathbb{D}}$, Laxmi Sushama ${ }^{1,2}$ and Ram Yerubandi ${ }^{3}$ \\ 1 Department of Civil Engineering, McGill University, Montreal, QC H3A 0C3, Canada; \\ bernardo.teufel@mail.mcgill.ca (B.T.); laxmi.sushama@mcgill.ca (L.S.) \\ 2 Trottier Institute for Sustainability in Engineering and Design, McGill University, \\ Montreal, QC H3A 0C3, Canada \\ 3 Water Science and Technology Division, Environment and Climate Change Canada, \\ Burlington, ON L7R 4A6, Canada; ram.yerubandi@ec.gc.ca \\ * Correspondence: guziy.sasha@gmail.com
}

Citation: Huziy, O.; Teufel, B.; Sushama, L.; Yerubandi, R. Heavy Lake-Effect Snowfall Changes and Mechanisms for the Laurentian Great Lakes Region. Atmosphere 2021, 12, 1577. https://doi.org/10.3390/ atmos12121577

Academic Editors: Baojie He, Ayyoob Sharifi, Chi Feng and Jun Yang

Received: 15 October 2021

Accepted: 26 November 2021

Published: 27 November 2021

Publisher's Note: MDPI stays neutral with regard to jurisdictional claims in published maps and institutional affiliations.

Copyright: (C) 2021 by the authors Licensee MDPI, Basel, Switzerland. This article is an open access article distributed under the terms and conditions of the Creative Commons Attribution (CC BY) license (https:/ / creativecommons.org/licenses/by/ $4.0 /)$.

\begin{abstract}
Heavy lake-effect snowfall (HLES) events are snowfall events enhanced by interactions between lakes and overlying cold air. Significant snowfall rates and accumulations caused during such events disrupt socioeconomic activities and sometimes lead to lethal consequences. The aim of this study is to assess projected changes to HLES by the end of the century (2079-2100) using a regional climate model for the first time with 3D representation for the Laurentian Great Lakes. When compared to observations over the 1989-2010 period, the model is able to realistically reproduce key mechanisms and characteristics of HLES events, thus increasing confidence in future projections. Projected changes to the frequency and amount of HLES suggest decreasing patterns, during the onset, active and decline phases of HLES. Despite reduced lake ice cover that will allow enhanced lake-atmosphere interactions favouring HLES, the warmer temperatures and associated increase in liquid to solid precipitation ratio along with reduced cold air outbreaks contribute to reduced HLES in the future climate. Analysis of the correlation patterns for current and future climates further supports the weaker impact of lake ice fraction on HLES in future climates. Albeit the decreases in HLES frequency and intensity and projected increases in extreme snowfall events (resulting from all mechanisms) raise concerns for impacts on the transportation, infrastructure and hydropower sectors in the region.
\end{abstract}

Keywords: lake-effect snowfall; regional climate modelling; climate change; Great Lakes; mechanisms

\section{Introduction}

Heavy lake-effect snowfall (HLES) events are winter snowstorms resulting from the rapid modification of cold air masses passing over the relatively warm waters of large lakes. First, the overlying atmosphere is destabilised through strong vertical fluxes of heat and moisture from water to air. Once the moisture-laden air hits land, the increased surface roughness causes convergence and upward vertical motion, resulting in HLES. These extreme events are frequent during the cold season downwind of the Laurentian Great Lakes, which provide large areas for lake-atmosphere interactions and are often on the way of the north-westerly flow of cold air coming from the Canadian North. The frequency of cold air outbreaks (CAO) [1,2] is one of the important factors controlling HLES [3,4]. The high snow rates and accumulations during HLES $[3,5,6]$ often disrupt the transportation, infrastructure and hydropower sectors, and other socioeconomic activities [3]. For example, in November 2014, one of the heaviest lake-effect snowfall events on record resulted in the death of more than a dozen people, as thousands of motorists were trapped in vehicles, falling trees triggered power outages and hundreds of roofs and structures collapsed under the weight of the snow. 
Given their impacts, it is important to understand how the frequencies, intensities and timings of these events will change in future climate. Previous studies have quantified projected changes to HLES for the Great Lakes region using one-dimensional (1D) lake models [3]. Notaro et al. [3] reported decreases in HLES during the 21st century, although slight increases are noted by the middle of the century around Lake Superior under Representative Concentration Pathway 8.5 (RCP8.5) for one of the two considered driving global climate models (GCMs). Under doubled $\mathrm{CO}_{2}$ concentrations, Janoski et al. [7] found decreases in mean snowfall across the Great Lakes region, but no significant changes to extreme snowfall, using a GCM at $\sim 50 \mathrm{~km}$ resolution.

One-dimensional lake models do not adequately simulate mixing processes [8,9], leading to biases in lake surface temperature and ice concentration. Furthermore, 1D models cannot capture the circulation patterns and currents, which also determine the lake ice onset and offset. Offline simulations, in which lake and atmospheric runs are performed separately, cannot capture the two-way feedbacks between the lake and the atmosphere. Given that HLES is generally confined to a narrow region on the lee shores of the lakes, the spatial resolution of GCMs is too coarse to resolve this phenomenon, and downscaling using regional climate models (RCMs) is required. Therefore, this study considers a coupled system consisting of the Nucleus for European Modelling of the Ocean (NEMO; Madec et al. [10]) coupled to the limited-area version of the Global Environment Multiscale (GEM) model to study HLES and associated mechanisms in current and future climates over the Laurentian Great Lakes region (Figure 1). Projected changes to HLES amounts and frequencies produced by the coupled system are analysed and linked to the projected warming, lake ice cover and precipitation changes in this study. The NEMO model coupled with GEM was used for the same region in previous studies in weather forecast mode [11], which showed that it is able to reproduce surface currents, lake ice fractions and lake surface temperatures well.

\section{Experimental domain}

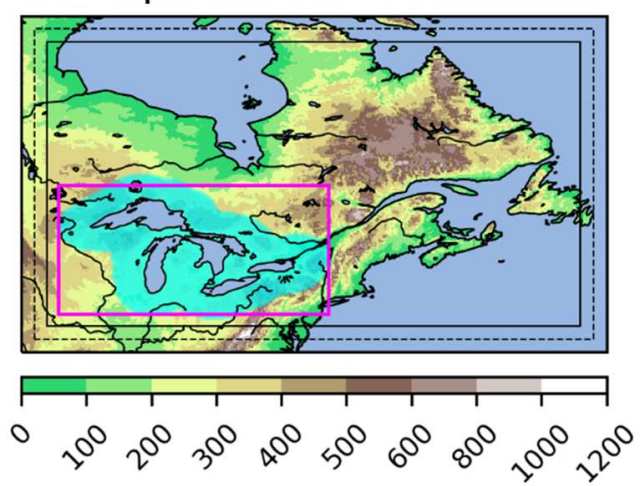

Figure 1. Experimental domain with topography $(\mathrm{m})$ shown in color. The region between the inner blue solid and dashed lines is the blending zone (10 grid points wide) and the region outside the dashed rectangle is the pilot zone (10 grid points wide). The region around the Great Lakes, highlighted in cyan color, is the $200 \mathrm{~km}$ near-shore zone and the magenta rectangle shows the region used for analysis.

The paper is organised as follows: Section 2 describes the model, simulations, and methods. Section 3 deals with model evaluation. Projected changes to HLES are presented in Section 4. Finally, the summary and conclusions are presented in Section 5.

\section{Models and Methods}

The regional climate model used in this study is the limited-area version of the Global Environment Multiscale (GEM) model used for numerical weather prediction by Environment and Climate Change Canada [12]. The following physical parameterisations are used in GEM: deep convection by Kain and Fritsch [13], shallow convection by Kuo [14], large- 
scale condensation by Sundqvist et al. [15], correlated-K solar and terrestrial radiations by $\mathrm{Li}$ and Barker [16], subgrid-scale orographic gravity-wave drag by McFarlane [17], lowlevel orographic blocking parameterisation by Zadra et al. [18,19] and planetary boundary layer parameterisation by Benoit et al. and Delage et al. [18,20-22]. The land surface scheme is the Canadian LAnd Surface Scheme (CLASS), version 3.5 [23,24]. This version of CLASS uses a flexible soil layering scheme, i.e., the number of soil layers and their thickness can be adjusted as required. CLASS includes prognostic equations for energy and water conservation for the soil layers and a thermally and hydrologically distinct snowpack (treated as a variable-depth layer) where applicable. The sub-grid lakes are represented by the 1D Hostetler lake model $[25,26]$, while resolved lakes such as the Laurentian Great Lakes are represented by the 3D ocean model NEMO with the Louvain-la-Neuve sea Ice Model (LIM3) for lake ice processes [27]. The timestep used for GEM in this study is $300 \mathrm{~s}$, and information is exchanged between GEM and NEMO every $30 \mathrm{~min}$, which is the timestep used for NEMO. The horizontal resolution used for both GEM and NEMO is 0.1 degrees. In NEMO, a 23-level z-coordinate with partial step bathymetry is used, in which layer thickness increases with depth. In LIM3, five ice categories are used to represent the sub-grid-scale ice thickness distribution. Each category is further vertically divided into one layer of snow and several ice layers of equal thicknesses.

To assess projected changes to heavy lake-effect snowfall, two 22-year-long simulations for the current 1989-2010 (GEM_NEMOc) and future 2079-2100 (GEM_NEMOf) periods are performed, driven by the second generation of the Canadian Earth System Model (CanESM2) for RCP8.5, a high-warming scenario characterised by increasing emissions throughout the 21st century. Water temperatures for the Great Lakes are initialised from a continuous (1950-2100) offline NEMO simulation driven by atmospheric fields produced by a previous CanESM2-driven transient climate change GEM simulation for the same emissions scenario at $0.44^{\circ}$ resolution. Land surface conditions are initialised from the same $0.44^{\circ}$ resolution GEM simulation. The temperature profiles for sub-grid lakes are initialised to $4.2^{\circ} \mathrm{C}$, except for the surface and the top layer, where the temperatures are set to $5^{\circ} \mathrm{C}$ and $10{ }^{\circ} \mathrm{C}$, respectively to represent the effects of surface cooling and residual heat from the preceding warm season, given the sparsity of observation data for smaller lakes in the study region (the simulations in the current and future climates were initialised in winter). Prior to assessing projected changes to HLES, the ability of GEM_NEMOc in simulating such events and their drivers is assessed through comparison with observations.

To objectively diagnose HLES from model outputs, the following fields are used: snowfall, lake ice fraction and wind fields. The algorithm for the HLES diagnostic is inspired by the work of Notaro et al. [3], which probes the 200-km region around the Great Lakes shorelines for intensive snowfall events (higher than $10 \mathrm{~cm} /$ day), that are associated with sufficient fetch over unfrozen lakes. Furthermore, to be considered an HLES, the snowfall within the $200 \mathrm{~km}$ zone surrounding the lake must be above the average snowfall for the $500 \mathrm{~km}$ zone around the lakes by $4 \mathrm{~cm} /$ day.

To determine projected changes to the temporal distribution of HLES, area-averaged values over the target region are analysed for current and future climates for the NovemberApril HLES period. The link between projected changes to HLES and $2 \mathrm{~m}$ air temperature, total precipitation and lake ice cover is established by studying the spatial change patterns during selected phases of the November-April period, as well as correlation maps for current and future climates. The linear correlation coefficients of HLES with $2 \mathrm{~m}$ air temperature and total precipitation are estimated using the collocated time series of seasonal mean values. To assess relations between HLES and lake ice cover, spatial mean lake ice fraction time series were correlated with HLES time series at each grid cell within the HLES region around the Great Lakes.

Given that extreme snowfall events (including, but not limited to HLES) have the potential to cause significant disruptions, projected changes to the intensity-frequency distribution of daily HLES and total snowfall are also assessed. To this end, the daily HLES and total snowfall over all gridcells of the analysis region (within $200 \mathrm{~km}$ of the Great 
Lakes shorelines) are used. The probability of daily snowfall exceeding diverse thresholds is calculated for both HLES and total snowfall, in both current and future climates. For the current climate, a bootstrapping procedure (consisting of 100 samples) based on selecting random days (with replacement) is employed to construct a confidence interval around the intensity-frequency curve, which allows for identifying statistically significant changes.

Since CAO are an important triggering mechanism for HLES, their climatology and projected changes are assessed following Wheeler et al. [1], where a grid cell is considered to be affected by $\mathrm{CAO}$ when the temperature is lower than 1.5 times the standard deviation below the 31-day running mean. Furthermore, a spatial continuity criterion is applied to ensure that the $\mathrm{CAO}$ affected grid points are contiguous and are associated with the same cold air mass. The applied criterion will also filter out regions smaller than $2^{\circ} \times 2^{\circ}(20$ by 20 grid points).

\section{Model's Ability in Simulating HLES and Its Drivers}

To assess the ability of GEM-NEMO in simulating the factors controlling HLES, the lake ice fraction simulated by GEM_NEMOc is compared to observations from Canadian Ice Service (CIS) and National Ice Center (NIC). Additionally, the CAO frequency in GEM_NEMOc is compared to that obtained from the Daymet [28] dataset, which is a $1 \mathrm{~km}$ horizontal resolution dataset derived from daily observations at weather stations. Figure 2 shows that GEM_NEMOc has a negligible bias in lake ice fraction for the onset (NovemberDecember; ND) and active (January-February; JF) phases, while it underestimates lake ice fraction during the decline (March-April; MA) phase. CAO occur in all three phases but are more frequent during the onset (ND) and active (JF) phases, peaking during the latter, in both observations and GEM_NEMOc. GEM_NEMOc slightly underestimates $\mathrm{CAO}$ frequency during the onset phase and slightly overestimates $\mathrm{CAO}$ frequency during the active and decline phases. In general, the GEM-NEMO modelling system performs reasonably well at simulating the factors and mechanisms leading to HLES.
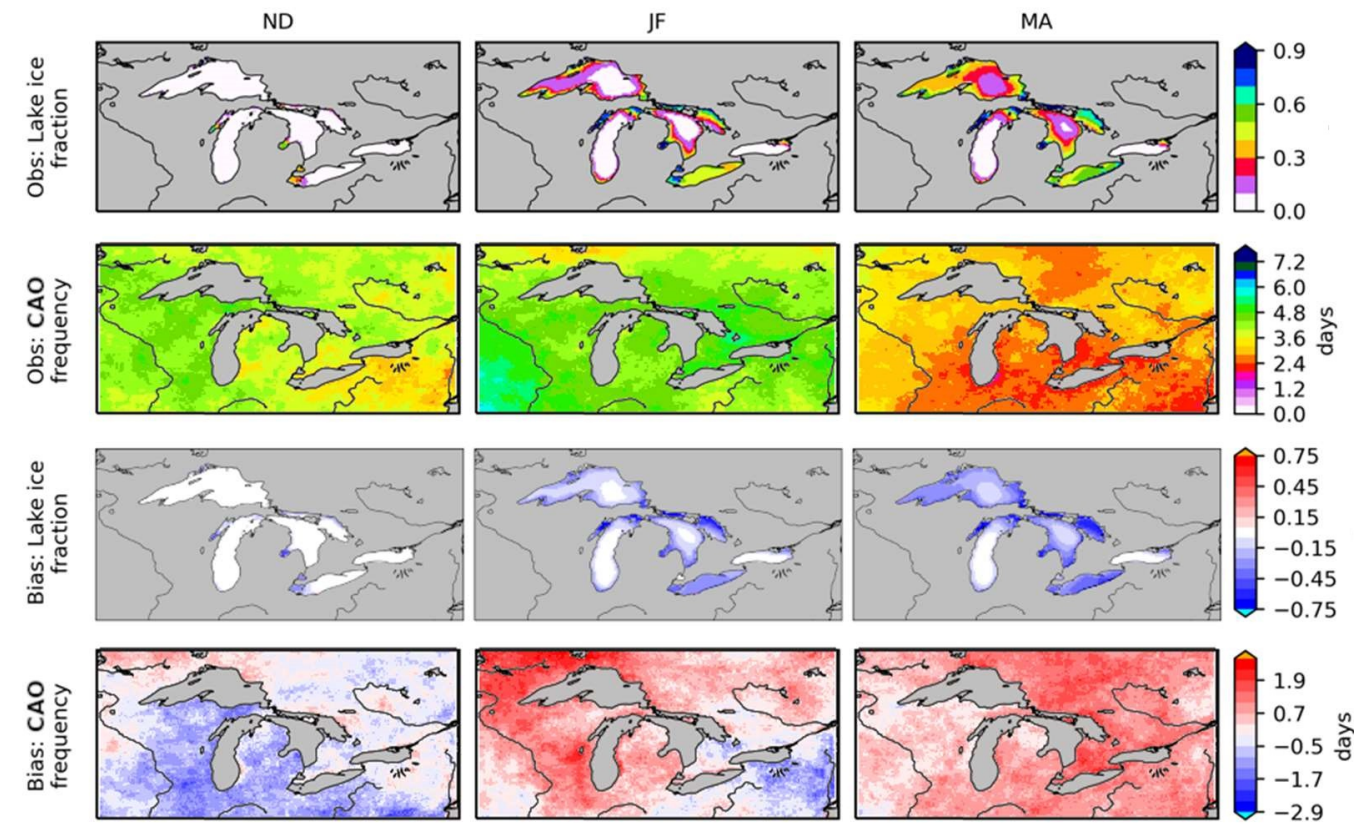

Figure 2. Observed fields (upper rows) and corresponding biases (lower rows) in the GEM_NEMOc simulated mean climatologic lake ice fraction and CAO frequency for the November-December (ND), January-February (JF), March-April (MA) periods of the 1989-2010 period. CAO frequency is not shown over the Great Lakes due to lack of reliable observation data.

To assess the ability of GEM-NEMO in simulating HLES realistically in current climate, GEM_NEMOc simulation spanning the 1989-2010 period, driven by CanESM2 outputs 
at the lateral boundaries, is compared to observations. The observed HLES is obtained by applying the algorithm described in the Methods section; the observed data used for the detection of HLES are as follows: total precipitation and $2 \mathrm{~m}$ air temperature fields from Daymet dataset [28], wind field from ERA-Interim reanalysis and lake ice fraction observations from Canadian Ice Service (CIS) and National Ice Center (NIC).

The GEM_NEMOc simulation captures well the spatial variability of HLES (Figure 3) but underestimates the frequency and magnitude of HLES, particularly downwind of Lake Superior and Huron. Investigation of the $2 \mathrm{~m}$ air temperature, total precipitation and lake ice fraction suggests that this underestimation is due to warm biases in the northern part of the study domain. The monthly distribution of the HLES amounts during the cold season is captured well by the model (figure not shown). The spatial correlations of modelled and observed HLES for ND, JF, and MA phases are, respectively, 0.74, 0.75 and 0.75 . The correlation values for HLES frequencies are similar, i.e., 0.76 for the three phases.
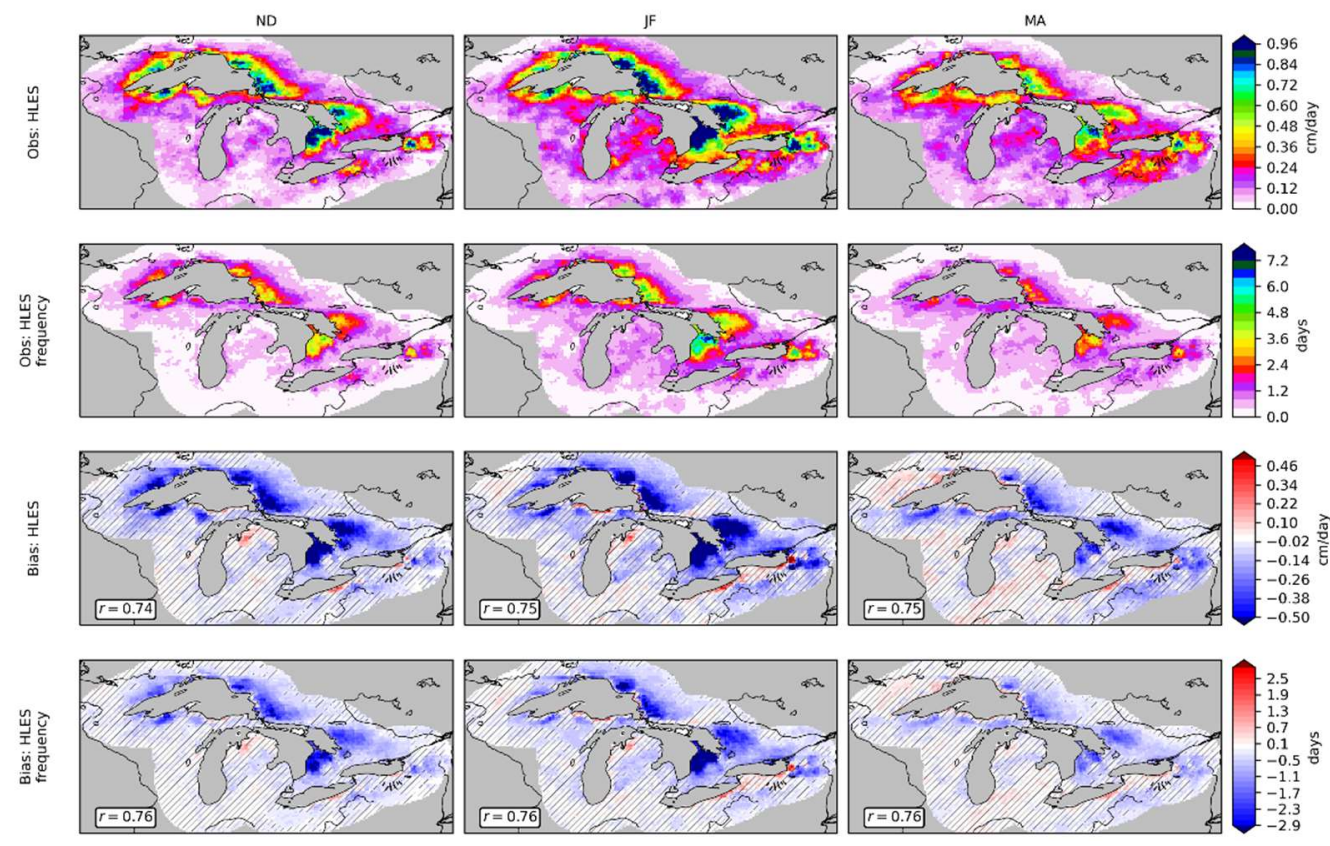

Figure 3. Observed fields (upper rows) and corresponding biases (lower rows) in the GEM_NEMOc simulated mean climatologic HLES ( $\mathrm{cm} /$ day) and HLES frequency (days) for the NovemberDecember (ND), January-February (JF), March-April (MA) periods of the 1989-2010 period. Biases not significant at $10 \%$ significance level are hatched. Biases are not shown for the Great Lakes due to lack of reliable observation data.

\section{HLES Characteristics in Current and Future Climates}

The coupled system used in this study captures well HLES as demonstrated by the comparison between observed and GEM simulated HLES when driven by CanESM2 outputs at the lateral boundaries (see Figure 3) for the 1989-2010 period. The model reproduces the temporal and spatial patterns realistically, with maximum HLES occurring in January. Spatial correlations of simulated and observed HLES and that of other related variables for the HLES onset (ND), active (JF) and decline (MA) phases are larger than 0.6. This gives confidence to consider the coupled system to assess future changes. Comparison of GEM_NEMOf with GEM_NEMOc suggests decreases to the total cold season HLES in the region by $71 \%$. The spatial and temporal differences in HLES are analysed further in detail in the following sections to gain a better understanding of the processes leading to the changes. 


\subsection{Spatio-Temporal Changes to HLES}

In simulations of the current climate, HLES occurs during the November to April period, with maximum HLES occurring during the month of January (Figure 4), in agreement with observations. The HLES amounts for the months of October and May are less than $1 \%$ of the total received and are therefore not considered. In future climates, HLES amounts are significantly reduced during the entire HLES period, with most of the HLES occurring during the December to March period. For a detailed analysis of processes, the HLES onset, active and decline phases are considered. Spatial patterns of projected changes to HLES for these three phases (Figure 5) suggest decreases with the largest absolute decreases for JF. These decreases are due to decreases in the HLES frequency as reflected in the spatial patterns of changes for HLES rates and frequencies.

Analysis of the projected changes to lake ice fraction reveals important reductions for the active and decline phases. Changes are minimal for the onset phase as lakes are generally ice-free even in the current climate. The decrease in HLES during the onset phase in future climate, despite the availability of open water, is primarily due to the decrease in CAO days and also due to the higher liquid to solid precipitation ratio in a future warmer climate; the warmer air temperature in future climate leads to rainfall as opposed to snowfall in the current climate. This is reflected in the spatial plots of projected changes to snowfall, which show decreases, despite an increase in precipitation. As for the active JF phase, even though lake ice fraction is reduced in future climate, the decrease in HLES seems to be more related to the reduced snowfall associated with increased rainfall to snowfall ratio in future climate as significant changes to $\mathrm{CAO}$ are not noted. The decline phase HLES decreases are very similar to that of the onset ND phase, with both precipitation phase and $\mathrm{CAO}$ decreases contributing.

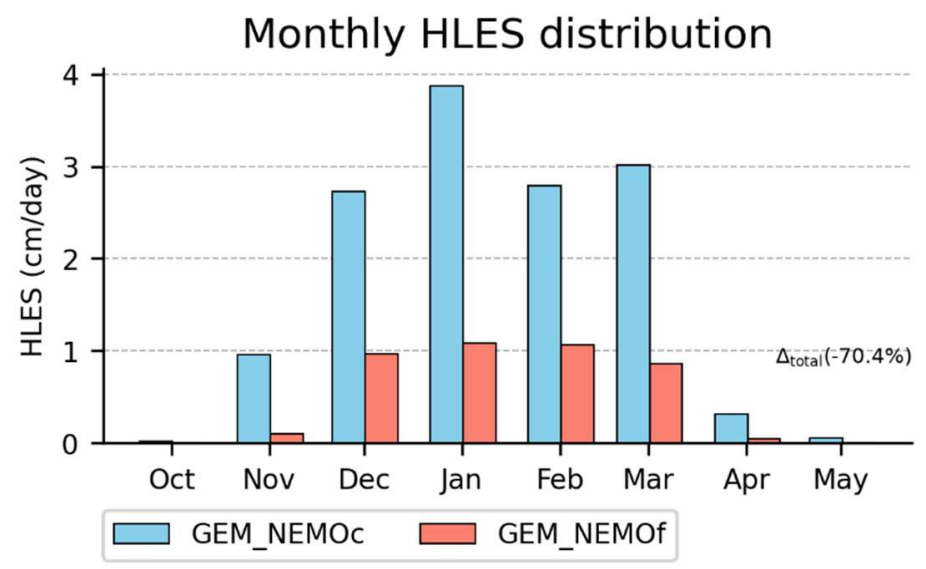

Figure 4. Modelled monthly distribution of area-averaged HLES (cm/day) for the current 1989-2010 (blue, GEM_NEMOc) and future 2079-2100 (red, GEM_NEMOf) periods. 

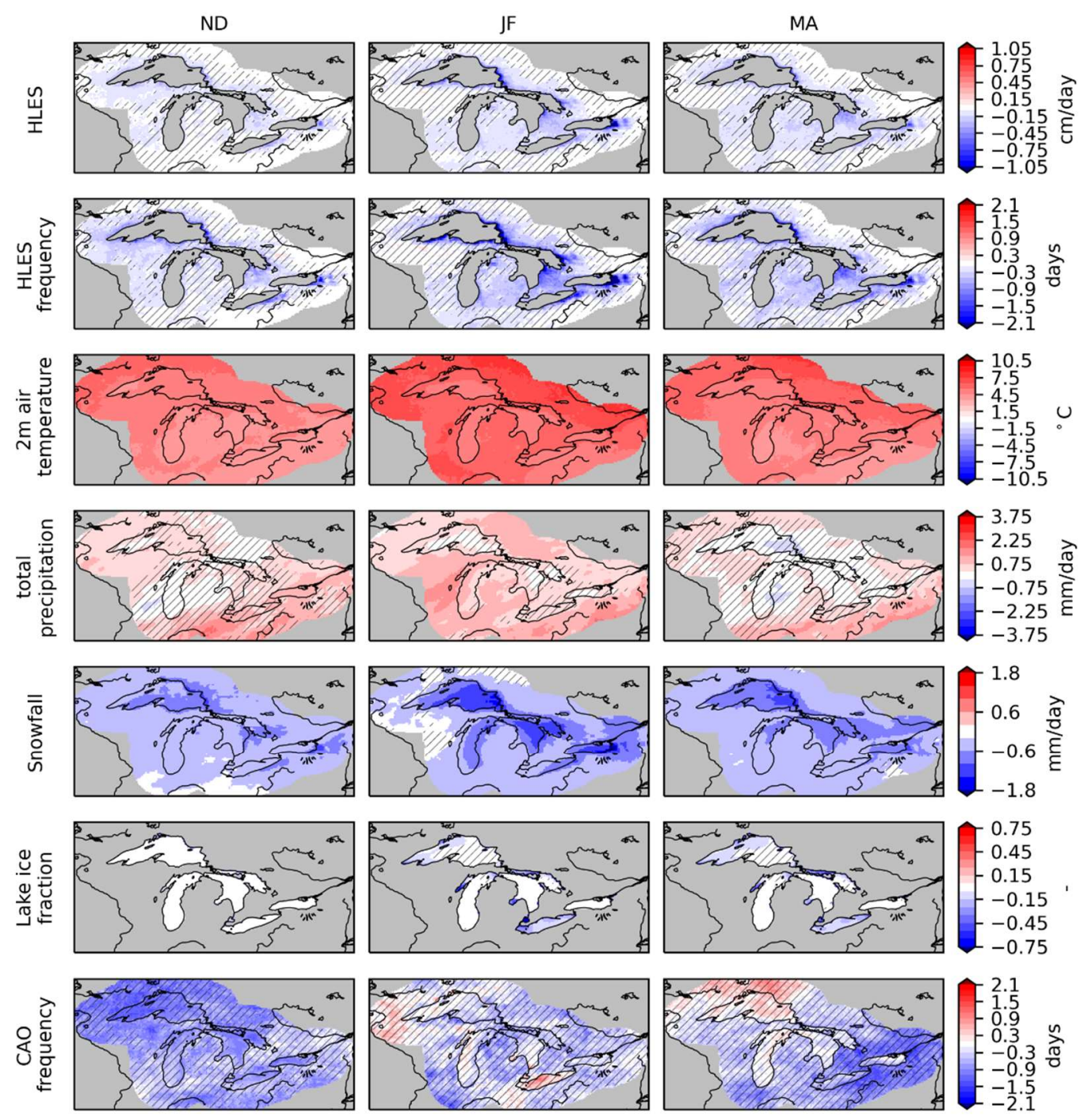

Figure 5. Projected changes to HLES (cm/day), HLES frequency (days), $2 \mathrm{~m}$ air temperature $\left({ }^{\circ} \mathrm{C}\right)$, total precipitation (mm/day), snowfall (mm/day), lake ice fraction, and cold air outbreaks (days) for the onset (ND), active (JF) and decline (MA) phases, for the 2079-2100 period with respect to the 1989-2010 period, for RCP8.5 scenario. Grid cells with no significant changes at $10 \%$ significance level are hatched.

\subsection{Relative Importance of HLES Mechanisms in Current and Future Climates}

To further investigate the links of HLES amount with air temperature, total precipitation and lake ice cover, the corresponding correlation maps are analysed for current and future climates for the three HLES phases. The correlations of HLES with surface air temperature in the current climate are predominantly negative for all three phases (Figure 6). There are different ways in which temperature can influence HLES. The importance of these influences on HLES is the direct effect of temperature on the precipitation phase and the indirect effect of temperature through its impact on lake ice fraction. The former is suggestive of negative HLES-temperature correlations, while the latter may lead to positive correlations. These correlations stay negative in future climate, particularly during the active JF phase, suggesting that the impact of $2 \mathrm{~m}$ temperature on HLES is mostly through its direct effect on the precipitation phase. For the shoulder ND and MA phases, a mix of positive and negative correlations are noted for future climate suggesting that $2 \mathrm{~m}$ temperatures influence both lake ice fraction and precipitation phase are important for HLES. 

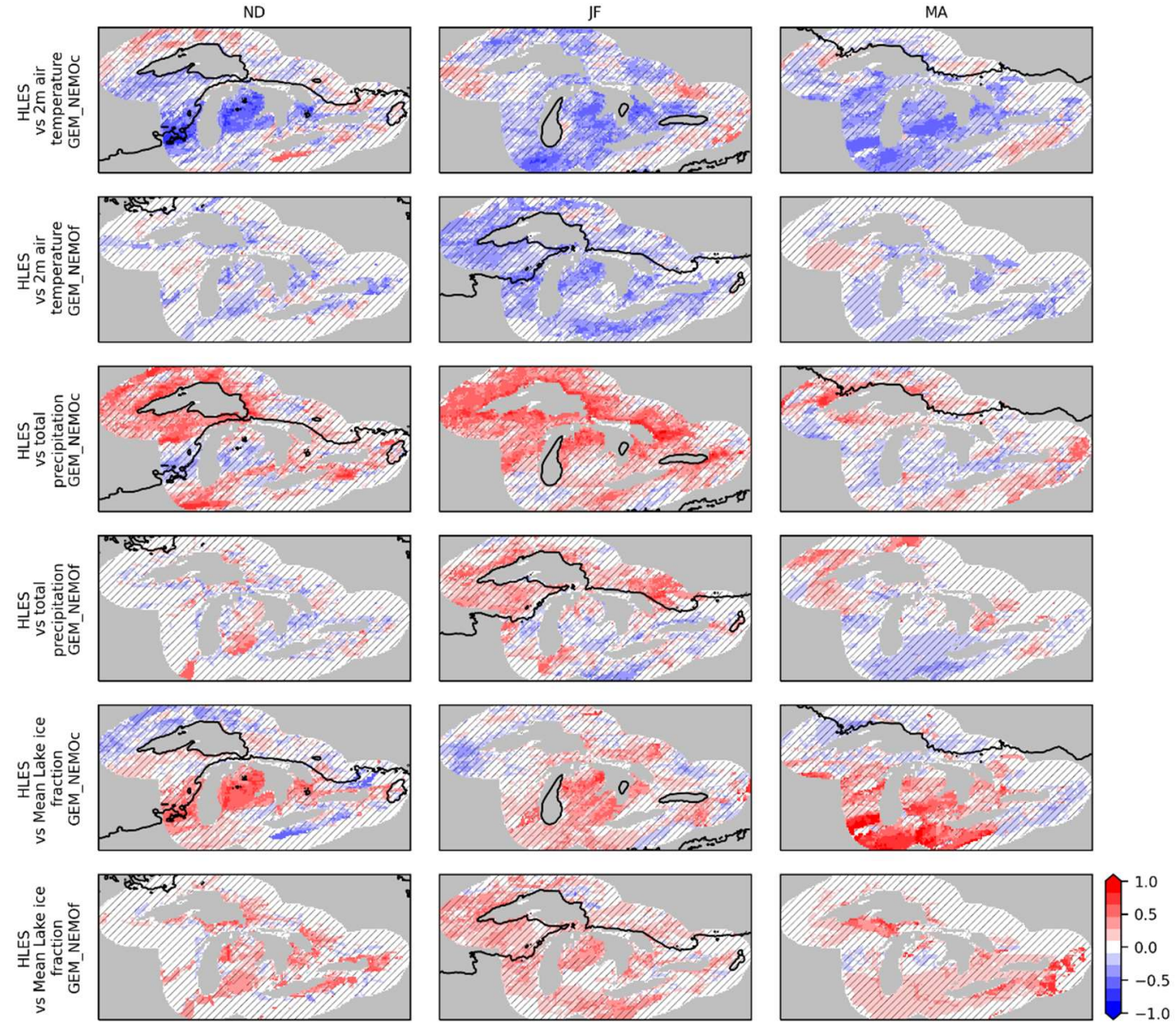

Figure 6. Correlation maps of HLES amount with respect to $2 \mathrm{~m}$ air temperature, total precipitation and lake ice fraction for the onset (ND), active (JF) and decline (MA) phases, for the 1989-2010 period (GEM_NEMOc) and the 2079-2100 period (GEM_NEMOf). Grid cells with no significant correlations at $10 \%$ significance level are hatched.

The positive HLES-precipitation correlations in the current climate weaken or become negative in future climate due to the higher liquid to solid precipitation ratios in the future and is consistent with the more negative HLES-2m temperature correlations discussed above. The negative correlations of the spatial mean lake ice cover with HLES during the current climate, mostly noted to the north and east of the lakes, suggest the dominant influence of lake ice in those regions. The obtained positive correlations for future climate suggest the weakening influence of lake ice fraction on HLES.

\subsection{Intensity of HLES and Total Snowfall in Current and Future Climates}

Given that extreme snowfall events (irrespective of the driving mechanism) have the potential to cause significant disruptions, projected changes to the intensity-frequency distribution of daily HLES and total snowfall are assessed over the region within $200 \mathrm{~km}$ of the Great Lakes shorelines. The $~ 70 \%$ projected decrease in both HLES frequency and amount (see Figures 4 and 5) is also reflected in the intensity of HLES events, which is projected to decrease for extreme HLES events producing daily accumulations in excess of $40 \mathrm{~cm}$ (Figure 7). While total snowfall (see Figure 5), and snowy days (daily snowfall $>1 \mathrm{~cm}$ ) are projected to decrease over the analysis domain, the most extreme snowfall events (daily snowfall $>50 \mathrm{~cm}$ ) are projected to increase in frequency and intensity, with a number of future events projected to exceed the heaviest event in the current climate (Figure 7), suggesting that extreme snowfall-related impacts will continue and might increase in the future climate. 

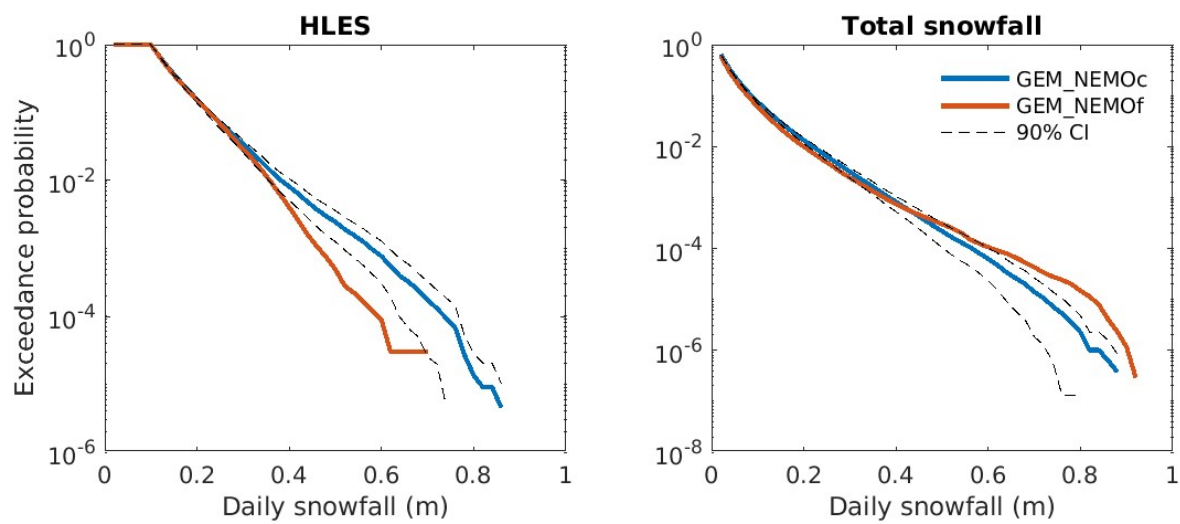

Figure 7. Intensity-frequency diagrams for HLES (left) and total snowfall (right) over the region within $200 \mathrm{~km}$ of the Great Lakes shorelines, for the 1989-2010 period (GEM_NEMOc, blue lines) and the 2079-2100 period (GEM_NEMOf, red lines). The 90\% confidence interval for the 1989-2010 period is shown with black dashed lines.

\section{Conclusions}

This work presents a systematic analysis of the spatiotemporal characteristics of projected changes to heavy lake-effect snowfall for the Laurentian Great Lakes region, based on current and future simulations of a regional climate model coupled with NEMO for the Laurentian Great Lakes region. The analysis considers the onset, active and decline phases of HLES to study contributions of involved mechanisms: indirect temperature effect via lake ice, and direct temperature impact on the precipitation phase. Results suggest that HLES will decrease during the entire November to April HLES period, similar to Notaro et al. [3], despite the reduced lake ice cover fractions in the warmer future climate due to a lower fraction of precipitation falling as snow. Cold air outbreaks also generally decrease, except for the active phase, but do not contribute to increasing HLES due to the direct effect of warmer temperatures on the precipitation phase. A particularly interesting result, showing how the link between air temperature, lake ice cover and HLES can be modulated by the changing climate, suggests that the dominant role of lake ice fraction on HLES in current climate weakens in future climate, particularly for the active and decline phases of HLES.

While the number of lake-effect snow events is projected to decrease significantly because of fewer below freezing days by the end of the 21st century, it is possible that HLES might increase in the near future as lake temperatures rise while winter air temperatures remain cold enough to produce snow, continuing the trend of increasing HLES observed in recent decades. Both increases and decreases to HLES would have significant implications for communities and hydrologic systems that are influenced by lake-effect precipitation. Since snowfall-related impacts occur regardless of the driving mechanism, this study also analysed all extreme snowfall events, which are projected to increase in frequency and intensity in future climates. The implications include expenditures for snow removal, changes in soil moisture, lake and river levels and spring flooding, along with impacts on the agricultural, hydropower, recreational and transportation sectors.

It is recognised that this study does not cover all possible uncertainties related to the regional climate model formulation and driving data. Therefore, it is desirable to extend this study to include an ensemble of RCMs, driven by multiple GCMs for a variety of scenarios of future climates. This study nevertheless provides useful insights regarding future HLES characteristics and controlling mechanisms and represents the first study to assess projected changes to HLES and its mechanisms using a 3D lake model. 
Author Contributions: Conceptualisation, L.S. and O.H.; methodology, L.S. and O.H.; software, O.H.; formal analysis, O.H. and B.T.; investigation, O.H. and B.T.; resources, L.S.; writing-original draft preparation, O.H. and L.S.; writing-review and editing, O.H., B.T., L.S. and R.Y.; visualisation, O.H. and B.T.; supervision, L.S.; project administration, L.S.; funding acquisition, L.S. and R.Y. All authors have read and agreed to the published version of the manuscript.

Funding: This research was funded by the Natural Sciences and Engineering Research Council (NSERC) of Canada (Grant Number: RGPCC 433915 - 2012) and Environment and Climate Change Canada (ECCC) (Grant Number: GCXE18S029).

Institutional Review Board Statement: Not applicable.

Informed Consent Statement: Not applicable.

Data Availability Statement: The data that support the findings of this study along with the analysis scripts are openly available in PANGAEA [29].

Acknowledgments: The research was enabled by the computing resources provided by Calcul Québec and Compute Canada.

Conflicts of Interest: The authors declare no conflict of interest.

\section{References}

1. Wheeler, D.D.; Harvey, V.L.; Atkinson, D.E.; Collins, R.L.; Mills, M.J. A climatology of cold air outbreaks over North America: WACCM and ERA-40 comparison and analysis. J. Geophys. Res. Atmos. 2011, 116. [CrossRef]

2. Yang, G.; Leung, L.R.; Jian, L.; Giacomo, M. Persistent cold air outbreaks over North America in a warming climate. Environ. Res. Lett. 2015, 10, 044001.

3. Notaro, M.; Bennington, V.; Vavrus, S. Dynamically Downscaled Projections of Lake-Effect Snow in the Great Lakes Basin. J. Clim. 2015, 28, 1661-1684. [CrossRef]

4. Vavrus, S.; Walsh, J.E.; Chapman, W.L.; Portis, D. The behavior of extreme cold air outbreaks under greenhouse warming. Int. J. Clim. 2006, 26, 1133-1147. [CrossRef]

5. Vavrus, S.; Notaro, M.; Zarrin, A. The Role of Ice Cover in Heavy Lake-Effect Snowstorms over the Great Lakes Basin as Simulated by RegCM4. Mon. Weather. Rev. 2013, 141, 148-165. [CrossRef]

6. Wright, D.M.; Posselt, D.J.; Steiner, A.L. Sensitivity of Lake-Effect Snowfall to Lake Ice Cover and Temperature in the Great Lakes Region. Mon. Weather. Rev. 2013, 141, 670-689. [CrossRef]

7. Janoski, T.P.; Broccoli, A.J.; Kapnick, S.B.; Johnson, N.C. Effects of Climate Change on Wind-Driven Heavy-Snowfall Events over Eastern North America. J. Clim. 2018, 31, 9037-9054. [CrossRef]

8. Bennington, V.; Notaro, M.; Holman, K.D. Improving Climate Sensitivity of Deep Lakes within a Regional Climate Model and Its Impact on Simulated Climate. J. Clim. 2014, 27, 2886-2911. [CrossRef]

9. Gula, J.; Peltier, W.R. Dynamical Downscaling over the Great Lakes Basin of North America Using the WRF Regional Climate Model: The Impact of the Great Lakes System on Regional Greenhouse Warming. J. Clim. 2012, 25, 7723-7742. [CrossRef]

10. Madec, G.; Delécluse, P.; Imbard, M.; Lévy, C. OPA 8.1 Ocean General Circulation Model Reference Manual; Notes du pôle de mode'lisation; laboratoire d'oce'anographie dynamique et de climatologie, Institut Pierre Simon Laplace des sciences de l'environnement global: Paris, France, 1998; Volume 11.

11. Dupont, F.; Chittibabu, P.; Fortin, V.; Rao, Y.R.; Lu, Y. Assessment of a NEMO-based hydrodynamic modelling system for the Great Lakes. Water Qual. Res. J. 2012, 47, 198-214. [CrossRef]

12. Cote, J.; Gravel, S.; Methot, A.; Patoine, A.; Roch, M.; Staniforth, A. The operational CMC-MRB Global Environmental Multiscale (GEM) model. Part I: Design considerations and formulation. Mon. Weather. Rev. 1998, 126, 1373-1395. [CrossRef]

13. Kain, J.S.; Fritsch, J.M. A One-Dimensional Entraining Detraining Plume Model and Its Application in Convective Parameterization. J. Atmos. Sci. 1990, 47, 2784-2802. [CrossRef]

14. Kuo, H.-L. On formation and intensification of tropical cyclones through latent heat release by cumulus convection. J. Atmos. Sci. 1965, 22, 40-63. [CrossRef]

15. Sundqvist, H.; Berge, E.; Kristjánsson, J.E. Condensation and cloud parameterization studies with a mesoscale numerical weather prediction model. Mon. Weather. Rev. 1989, 117, 1641-1657. [CrossRef]

16. Li, J.; Barker, H.W. A radiation algorithm with correlated-k distribution. Part I: Local thermal equilibrium. J. Atmos. Sci. 2005, 62, 286-309. [CrossRef]

17. McFarlane, N.A. The Effect of Orographically Excited Gravity Wave Drag on the General Circulation of the Lower Stratosphere and Troposphere. J. Atmos. Sci. 1987, 44, 1775-1800. [CrossRef]

18. Zadra, A.; McTaggart-Cowan, R.; Roch, M. Recent changes to the orographic blocking. In Proceedings of the Seminar presentation, RPN, Dorval, QC, Canada, 30 March 2012.

19. Zadra, A.; Roch, M.; Laroche, S.; Charron, M. The subgrid-scale orographic blocking parametrization of the GEM Model. Atmos Ocean 2003, 41, 155-170. [CrossRef] 
20. Benoit, R.; Cote, J.; Mailhot, J. Inclusion of a Tke Boundary-Layer Parameterization in the Canadian Regional Finite-Element Model. Mon. Weather. Rev. 1989, 117, 1726-1750. [CrossRef]

21. Delage, Y. Parameterising sub-grid scale vertical transport in atmospheric models under statically stable conditions. Bound. -Layer Meteorol. 1997, 82, 23-48. [CrossRef]

22. Delage, Y.; Girard, C. Stability Functions Correct at the Free-Convection Limit and Consistent for Both the Surface and Ekman Layers. Bound. -Layer Meteorol. 1992, 58, 19-31. [CrossRef]

23. Verseghy, D.L. CLASS-A Canadian Land Surface Scheme for GCMs.1. Soil Model. Int. J. Clim. 1991, 11, 111-133. [CrossRef]

24. Verseghy, D.L. Local climates simulated by two generations of Canadian GCM land surface schemes. Atmos Ocean 1996, 34, 435-456. [CrossRef]

25. Hostetler, S.W.; Bates, G.T.; Giorgi, F. Interactive Coupling of a Lake Thermal-Model with a Regional Climate Model. J. Geophys. Res.-Atmos 1993, 98, 5045-5057. [CrossRef]

26. Martynov, A.; Sushama, L.; Laprise, R.; Winger, K.; Dugas, B. Interactive Lakes in the Canadian Regional Climate Model, Version 5: The Role of Lakes in the Regional Climate of North America. 2012. Available online: https://www.tandfonline.com/doi/full/ 10.3402/tellusa.v64i0.16226 (accessed on 23 November 2021).

27. Vancoppenolle, M.; Bouillon, S.; Fichefet, T.; Goosse, H.; Lecomte, O.; Morales Maqueda, M.A.; Madec, G. LIM The Louvain-laNeuve Sea Ice Model; Note du Pôle de Modélisation de l'Institut Pierre-Simon: Laplace, France, 2012.

28. Thornton, P.E.; Running, S.W.; White, M.A. Generating surfaces of daily meteorological variables over large regions of complex terrain. J. Hydrol. 1997, 190, 214-251. [CrossRef]

29. Huziy, O. HLES projected changes study dataset. Pangaea 2020. [CrossRef] 